\title{
Obsesi Seorang Wiraswastawan
}

\author{
Oleh : Ahmad Muhadi
}

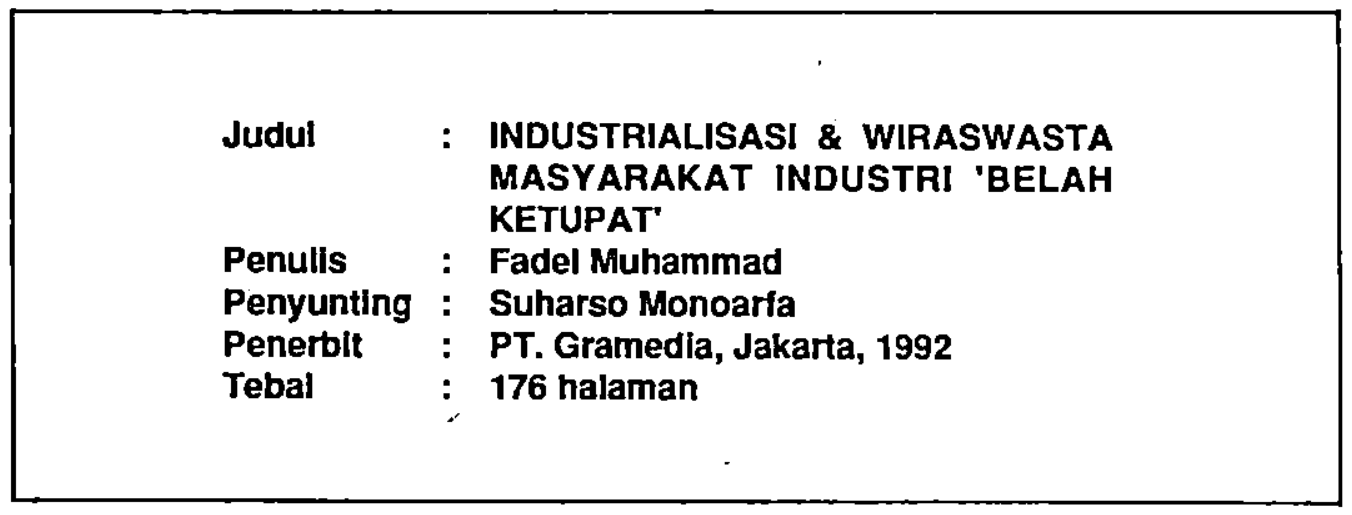

Sebuah buku yang terjelma dari kompilasi berbagai makalah seminar dan diskusi, akhir-akhir ini menjadi 'mode' bagi para penulis kita. Menulis sebuah buku yang langsung jadi, memang tidaklah mudah, apalagi bagi orang seperti Fadel Muhammad ini yang sangat sibuk sebagai praktisi. Persoalan waktu, tentu menjadi pertimbangan.

Barangkali buku yang diberi judul : Industrialisasi \& Wiraswasta; Membangun Masyarakat Industri 'Belah Ketupat' ini bukanlah terjelma hanya oleh kejelian penyunting meramu kumpulan makalah saja, tetapi nampaknya Fadel telah mensiasati skenario membuat sebuah buku - meski ada sedikit terasa mengulang-ulang. Namun tidak begitu kentara bahwa buku ini sesungguhnya merupakan kumpulan makalah. Karena bahasanya yang konsisten, analisis . yang berimbang dan karakter opini yang kuat; tercermin dalam bagian-bagian tulisannya.
Maka setelah membaca buku ini kita seolah-olah dibawa kepada alam obsesi yang kuat ke arah pemikiran paradigma sebuah ilmu baru : Industri. Proses dialektika ilmu, thesa-antithesa yang sangat analisis, membawa buku ini nyaris menjadi sebuah teori baru.

Pembaca boleh saja setuju atau tidak setuju terhadap thesis yang diungkapnya, yaitu bahwa industrialisasi bukanlah hantu yang ditakuti. Tetapi harus kita terima sebagai kenyataan. Maka pendekatan industrialisasi Indonesia harus berstruktur 'belah ketupat', bukan piramida. Belah ketupat ini sebenarnya terbentuk dari dua piramida : satu menghadap ke atas dan satunya ke bawah.

Persoalannya mengapa harus berstruktur belah ketupat ? Menurutnya, bangsa kita mempunyai tujuan yang ideal yaitu adil dan makmur yang merata. Maka struktur belah ketupat mencerminkan masyarakat lapis. 
menengah yang memiliki economic power yang dominan; dan masyarakat lapis atas dan bawah yang minoritas.

Dan bagaimanakah kita dapat mencapai struktur belah ketupat itu ? Menurutnya sekurang-kurangnya ada empat strategi yang harus ditempuh, untuk mengubah struktur piramida ke belah ketupat sebagai kekuatan transformasi berlandaskan idealisme yaitu strategi industrialisasi, strategi pendidikan, strategi pengembangann masyarakat dan strategi korporasi.

Pertama, strategi industrialisasi adalah himpunan kebijaksanaan dan regulasi pemerintah yang menciptakan iklim yang kondusif dan mendorong masyarakat masuk ke dalam proses industrialisasi.

Kedua, strategi pendidikan diharapkan dapat menghasilkan suatu sumber daya manusia yang berkemampuan inovatif dan berkepemimpinan sebagai layaknya manusia industri.

Ketiga, strategi pengembangan masyarakat yaitu strategi yang mendorong masyarakat agar memiliki need achievement dan kewiraswastaan yang tinggi, sehingga dapat melahirkan manusia wiraswasta yang mendukung 'industri.

Keempat, strategi korporasi yang it mengarah kepada usaha pengembangan Indonesian incorporated, dengan memberikan kesempatan yang luas dan transparan untuk setiap value chain, dalam rangka pembentukan value system nasional, dan padá akhirnya menghasilkan struktur dunia usaha yang dinamis dan berdaya saing internasional.

Keempat strategi itu, menurut pandangannya menjadi suatu conditio sine qua non dalam menanggapi globalisasi, dengan terlebih dahulu menyiapkan dan memperkuat home base kita. Bayangkan, tulisnya, apa jadinya kita dalam arus deras globalisasi dengan kompetisi internasional yang kuat, jika kita masih dalam posisi piramida.

Jalan pikiran Fadel barangkali - mencerminkan dirinya sebagai seorang pelaku th. ekonomi: wiraswasta, yang tentu berwawasan ke depan. Maka rasanya pendapat para futurolog seperti Alvin Toffler, John Naisbitt dan Aburdene Patricia, Peter Drucker dan Michael Porter; tidak bisa ia lewatkan begitu saja. Namun hal yang perlu dicatat adalah bahwa apapun jalan pikiran para ahli tersebut tidak mampu menggeser pemikirannya tentang landasan idealisme industrialisasi di Indonesia.

Konsistensi pemikirannya sebagai anak bangsa ini menukik ke dalam Wawasan Nusantara : IPOLEKSOSBUD yang mendasarkan pada kesatuan wilayah geografis, transportasi dan energi, yang menurutnya sangat strategis. Karena itu, seyogyanya industri transportasi dan energi dikembangkan sebagai leading industri nasional, yang mampu menggerakkan roda industri nasional melalui upaya pengembangbiakan industri baik vertikal maupun horizontal.

Strategi industrialisasi masa depan menurutnya, memang tidak dapat menghindari globalisasi. Namun yang perlu diingat adalah bahwa tidak semua bangsa memasuki era globalisasi secara serempak. Masing-masing berupaya menyusun pendekatan antisipasi dan strategi yang berbeda. Kuncinya, menurut Fadel adalah penguasaan sains dan teknologi oleh manusianya. Karena itu, pengembangan sains dan teknologi hanya dapat diantisipasi oleh sumber daya manusia yang berkemampuan inovatif dan kepemimpinan.

Maka pendidikan ia pandang mempunyai arti yang luas menjadi jalur yang penting dalam mengupayakan transformasi itu. Pendidikan dan dunia usaha pada dasamya dapat bekerja sama, terutama dalam mengantisipasi kelemahan kegiatan Research and Development (R \& D). Sementara peran pengusaha lapis bawah dan tengah perlu digalang membentuk related and supporting industries, sehingga skala industri kelas bawah akan ter-transformasi menjadi kelas menengah. Disini, menurutnya Pemerintah 
harus berperan melalui pengaturan dan tata peraturan bisnis yang mendorong munculnya para wiraswasta baru. Sebab menurutnya wiraswasta ini akan membuka mata masyarakat untuk berapresiasi terhadapnya, sebagai cultural switch.

Keempat jalur strategi transformasi di atas, menurutnya pada hakikatnya merupakan upaya menciptakan suatu masyarakat industri yang berkemampuan inovatif dan kepemimpinan. Pada akhirnya, masyarakat industri Indonesia merupakan suatu masyarakat yang berdaya saing internasional dan yang menguasai serta menyetir industrinya sendiri.

Akankah ini hanya menjadi sebuah obsesi? Fadel berusaha menyajikan analisis bisnisnya - dari kelompok Bukaka Gema dalam bentuk tulisan pengalaman. Nampaknya ia berusaha meyakinkan pembacanya untuk membedakan antara pemikiran dan obsesi.

Yang jelas, dari ke 19 makalah yang dikelompokkan menjadi 6 bab dalam buku ini, tampaknya penyunting membuat plot parabolik. Sehingga dapat ditebak, bahwa klimaks buku ini ada pada sub judul : Peranan Sumber Daya Manusia dalam Dunia Usaha; Membangun Masyarakat Industri Indonesia 'Belah Ketupat'. Dan makalah klimaks ini pula yang direkam menjadi judul sampul buku ini.

Meskipun buku ini terkesan berbahasa 'praktis', namun terasa lengkap dan ilmiah. Gaya 'aku' asli dalam makalah masih terasa kuat, dan tampaknya inilah sisi penting dari buku ini, bahwa Fadel 'sempat' berteori tentang kewiraswastaan - yang menempatkan dirinya sebagai pemikir mutakhir diantara pemikir kewiraswastaan abad 20 - tepatnya di tahun 1992 ini. Pemikir sebelumnya adalah Robert Hisrich pada tahun 1985. Dan kalau kita lihat daftar pemikir tentang kewiraswastaan sejak abad 17, hanya Fadel pula yang berkebangsaan Indonesia.

(Akhmad Muhadi) 